\title{
TEOLOGÍA DE LA LIBERACIÓN EN COLOMBIA
}

\section{Andrea Mesa Villegas ${ }^{* *}$}

Si usted nunca ha escuchado acerca de la teología de la liberación, este libro es un buen acercamiento para saber de qué trata. Escrito en un lenguaje sencillo el historiador Antonio José Echeverry, hace un recuento histórico de cómo ha sido y es este proceso en Colombia desde la colonia, contextualizando local, continental y mundialmente con hechos las nuevas reflexiones religiosas, para dar a entender que los procesos de la teología de la liberación en Colombia son tanto resultado de un proceso como de circunstancias que la impulsan.

La teología de la liberación trata de responder el ¿cómo hablar de Dios a un mundo que no necesita hablar de Dios? A partir de este principio se trata de que los designios de Dios caminen a la par con la historia humana, creando un hombre nuevo que se amolde a la modernidad, pero sin dejar de lado su vida cristiana. ¿Cuál ha sido el proceso de la teología de la liberación en nuestro país? ¿Cuál es su importancia y para qué estudiarlo? Son las preguntas que trata de responder el autor en los siete capítulos de su libro "Teología de la liberación en Colombia" realizando una reflexión, como él la llama, históricohermenéutica del proceso, en la que se tiene en cuenta lo que pensaban quienes la crearon y desde qué contexto se pensó.

Si la teología de la liberación tiene como objeto la fe de los pobres, entonces ¿Quiénes son los pobres? El autor hace una distinción de los más necesitados: en la América colonial el pobre era el indígena y a él se enfocaba el trabajo de aquellos que buscaban su bienestar. Ya para el siglo XVII los desposeídos fueron los esclavos; he aquí un fragmento en el que 
el autor se refiere a Sandoval, primer clérigo que pide la atención de la Iglesia sobre los negros: "Sandoval, como hombre de su tiempo, a los señores pedirá clemencia y moderación y a los negros resignación y certeza de la justicia de Dios en la otra vida” Hoy el pobre se entiende dentro de las dinámicas socio - económicas, mas allá de las distinciones raciales, ese es el objeto de acción de los que abanderan estas ideas liberadoras. "La Iglesia en Colombia se percata tardíamente que el país estaba urbanizado, que necesitaba mantener su influencia sobre las masas populares a través de las devociones religiosas, y tenía que entrar a competir con asociaciones laicas, grupos políticos, cultos animistas de origen africano y las recientemente introducidas iglesias evangélicas o mal llamadas "protestantes". La Iglesia entonces busca recuperar su lugar central en la sociedad, construyendo un nuevo proyecto de fe cristiana, el cual abarca el apoyo a la creación de grupos como la U.T.C. (Unión de Trabajadores de Colombia) en 1945, y en 1950 para acrecentar su influencia entre los laicos, crea grupos de jóvenes tales como Juventud Obrera Católica, Movimiento Universitario Católico, entre otros. Estas asociaciones buscaban preparar dirigentes laicos, cuyas tareas eran, aumentar la ayuda misionera extranjera, la investigación y la documentación social.

A pesar de la creación de estos grupos, serían las CEBs (Comunidades Eclesiales de Base), las de más trascendencia en Colombia. Estas son como pequeñas células de la Iglesia, conformadas por habitantes de sectores pobres o marginados con proximidad vecinal, que se unen a partir de su fe cristiana, permitiendo la participación del pueblo en la relectura de la Biblia desde la perspectiva del pobre y la reflexión sobre la realidad social.

\footnotetext{
*** Estudiante de Licenciatura en Historia y Comunicación Social, Univalle. andreamv@ univalle.edu.co
} 
La Teología de la Liberación, en los últimos años ha sido criticada desde la oficialidad, sin embargo aún el debate sobre su accionar se alimenta, y mas si se tiene en cuenta que: "El Evangelio de Jesucristo es un mensaje de libertad y una fuerza de liberación” 